\title{
The Future of Agricultural Economics in Extension
}

\section{Stephen H. Amosson}

Many scholars in our profession have addressed the decline of Extension and potential remedies. Dana Hoag did an excellent job in reviewing these studies, as well as providing his view on potential solutions. It is interesting to note that virtually all of these scholars have come from situations in which Extension has declined. In this short presentation, I do not plan on regurgitating this information. In fact, I plan on narrowing my discussion to our profession within Extension and my views on what has made it successful in Texas, where full-time employees (FTEs) in our unit have actually increased during my career.

First, I must preface my discussion with stating the obvious. Funding for Extension has been and will continue to be under pressure. A declining clientele base, combined with the need to compete for funding with defense, education, welfare, etc., has led to real decreases in at least formula funding for both agricultural research and Extension. Our profession, being considered a "soft" science, puts us in an even more precarious position. However, recognizing and acknowledging the situation is always the first step in dealing with it.

I believe there are three basic functions in Extension that agricultural economists must perform to be successful. These are extensive educational activities, applied research, and intensive educational efforts. Each of these functions is important, but, I will argue, each can have significantly different funding implications. I will discuss each of these functions;

Dr. Stephen H. Amosson is Regents Fellow, professor, and Extension economist in the Department of Agricultural Economics, Texas A\&M University. however, I will focus on the latter, given the limited space I have.

\section{Extensive Educational Activities}

I define extensive educational activities as the delivery of basic data, informational programs, and workshops. This category would include enterprise budgets, crop insurance, tax law changes, commodity price outlook, farm policy, basic economic analysis, etc. The unbiased presentation of this information is an important and necessary function of Extension. Saying that, I believe it is the least valuable of the three functions. True, extensive programming builds name recognition with clientele groups and thus supporters. By supporters, I mean that clientele will tell you this is valuable information. However, when budgets get tight, these individuals will give only "lip-service" support.

Again, I do believe that this is a valuable function of Extension. However, the amount of time spent in the delivery of this information needs to be limited (not eliminated) and time redirected to more beneficial activities. It is imperative that we become more efficient in delivering this information while expanding the audience.

We do many good things in Texas for our producers; however, efficient delivery of information is one area in which we lag. Although some of this information is state-specific, a great deal of the information/analysis applies across states. States in the West and Midwest have done a good job in improving efficiency by sharing resources across state 
lines as Extension FTEs have decreased. The second part of efficiency in this area is improving the delivery system. I believe the approach that the University of Illinois has taken with the development of farmdoc (ivi is a very good example. This combination of e-mail and web delivery provides a cost-effective method of rapidly delivering information/analysis, as well as advertising programs, to a larger audience.

\section{Applied Research}

This is an area in which I believe opportunities will continue to expand for Extension professionals in our field. I believe this for two reasons. First, in virtually every request for proposals, an economic assessment of results is required, especially on multidisciplinary grant proposals. In addition, as accountability issues have risen in importance among government entities, most require an external economic feasibility study before implementing new policies. Again, this provides more opportunities for economists.

The second reason is a little more controversial. I believe our profession and incentive structure have created a void in the applied research area. The value of agricultural economics departments is often determined by the quantity and quality of refereed journal articles produced. Those that do the best are rewarded the most. Unfortunately, a majority of these articles are of little value (outside of our profession) to clientele groups.

I certainly don't blame the researchers. They are simply responding to the incentive system, which favors theoretical research over applied research. I've observed that as research FTEs have fallen over the years, the number of applied researchers has declined disproportionately to the number of theoretical researchers. This brings me to my point. The current lack of applied researchers, combined with the increased demand for their services, is providing the opportunity for Extension professionals to increase grant funding by stepping in to fill the void.

Why is applied research funding important? First, it adds additional resources that of- ten complement other efforts. Second, it creates supporters and sometimes advocates for Extension. I've defined supporters earlier, but not advocates. Advocates are clientele who will pick up the phone, call a legislator or congressperson, and tell him or her that you are providing an essential service. They are willing cooperators in helping to obtain grants and other funding. How do you create advocates? Simple-you provide a service/analysis that affects the bottom line.

The best example of creating advocates within Extension is 4-H. In Texas, I've seen it time and time again when the budget is in trouble: $4-\mathrm{H}$ parents are the first to provide the most support by calling legislators. Another example is in Minnesota, where Extension was redesigned. Counties had the opportunity to select the type and number of agents for their area. A majority of the agents they chose to employ were 4-H agents. Why? Because what 4-H agents do results in creating or improving human capital, i.e., affecting the bottom line.

In Texas, we have done a good job in the applied research arena by following the "gap" principle. By the "gap" principle, I mean plugging the holes in applied research identified by our clientele, i.e., providing the analysis our clientele need to make informed decisions. Texas has many organizations that follow the "gap" principle and transfer applied research to the people who need and use it. We have an Agricultural \& Food Policy Center that provides analyses in support of Congress, the state legislature, and industry. We also have the Center for North American Studies, which provides international trade analyses to clientele groups. Personally, I have received funding from more than 90 grants, serving as project director on a majority of them. I believe my success is because of my willingness to undertake applied research projects, in which no other economists were interested, because I felt there was a benefit to my clientele. Another part of what has made me successful is following the "gap" principle. Initially, the grants may have been for small amounts of money. However, successfully completing the grant has generally led to 
further funding and more grant opportunities/ collaborations, i.e., success breeds success.

\section{Intensive Educational Efforts}

In my view, intensive educational efforts are essential elements to the long-term viability of Extension. Whereas extensive educational programming provides information and basic analysis, intensive educational efforts teach clientele how to correctly process this information and utilize it in their operations. The development and execution of an intensive educational program is labor-demanding and often expensive, but can be rewarding. If the intensive effort is successful, producers' incomes typically increase. By improving producers' financial health, you create advocates. As I stated before, advocates are the individuals who will call representatives and congresspersons to support funding or new funding initiatives.

Creating a successful intensive educational program is a painstaking, difficult process, especially in today's environment, where you are competing for a precious resource-producers' time. To successfully compete, programs must be targeted to a producer's area of interest. They need to be taught at an applied level (no theory) by the best instructors available, using a combination of teaching techniques such as simulation exercises, small group work, etc., to keep participants involved. There are a number of other factors I don't have space to mention, but the primary characteristic to remember regarding any intensive educational program effort can be expressed in three words: Quality ... Quality ... Quality.

Conducting a successful intensive educational program builds credibility with clientele groups. Conversely, a failed effort undermines credibility. Therefore, the design and execution of these efforts is critical to ensure the highest probability of success. I'm now going to discuss what I believe are the essential (not all) steps in developing and maintaining a successful intensive educational program. These steps include identification of the problem and potential solution, creating shared vision with- in, professional review/input, industry review/ input, and evaluation. To keep this from being a mundane lecture, I will illustrate the steps by using my experiences (as an individual and a team member) in developing and operating the award-winning Master Marketer Program. Finally, I'll end with the benefits that have resulted from this effort.

\section{Identification of the Problem and Potential Solution}

A number of producer surveys have been conducted over the years to identify/rank the risks and uncertainties producers face. Virtually all identify marketing as number one or two on that list (the other is always weather). However, in my experience, 1- or 2-day short courses on marketing resulted in very little implementation, and therefore very little impact. I decided that extended intensive education was required to effect change in producers" behavior. This course would need to be taught utilizing the best speakers available in order to draw participants. I realize that a number of scholars believe that markets are efficient and that therefore marketing education is not effective, and I'm not going to debate that point. Efficient markets seem logical to me; however, I have observed firsthand that some producers do a better job of marketing than others. I'm sure there is some logical explanation to bridge theory with reality, but I'll let others figure it out.

\section{Creating Shared Vision Within}

Creating shared vision can be difficult but is essential. I presented my idea at a meeting of our Extension economists, and it met with, at best, indifference. Later, my colleague encouraged me to continue to pursue the idea. Subsequently, our grain marketing specialist more clearly understood and wholeheartedly joined in my pursuit of developing this program; it then became "shared vision." This partnership was critical in developing and executing the program. In fact, without his commitment to the effort, I have no doubt the program would not exist. Eventually, two additional special- 
ists joined the team, which allowed for the expansion of activities associated with the program.

Shared vision is important for several reasons. I truly believe in the old adages "Two heads are better than one" and "The whole is greater than the sum of its parts." First, you are able to divide up the workload. Second, you have a "sounding board" to help evaluate the feasibility of implementing new or different ideas. Third, in case of health or other problems for a team member, there are individuals familiar with the program who can continue its progress. Finally, it is much easier to sell a program with multiple committed voices rather than one.

\section{Professional Review/Input}

It is important to obtain external input on content from other professionals in designing intensive educational programs. They can provide thoughts or suggestions that may have been overlooked in the initial design. We held a free session at the American Agricultural Economics Association annual meeting to discuss the Master Marketer concept. Eight to 10 marketing economists from across the country attended the session. These professionals were asked two questions. First, what did they think about the feasibility of the concept? (We received a mixed reaction, including a couple of comments that are not repeatable.) Second, what topics need to be taught in each course? Many excellent suggestions were received and subsequently incorporated into the 120- to 130 -hour training in marketing and risk management.

\section{Industry Review/Input}

A focus group consisting of clientele is an essential element in the design of any successful intensive educational program. If clientele don't endorse the concept, then the probability of success is slim. We constructed a focus group consisting of leading producers and lenders to review the concept, proposed agen$\mathrm{da}$, and program format. After 3 hours of dis- cussion, the focus group determined four basic conclusions and/or recommendations. This type of training is necessary and would be beneficial to producers. The subject matter needed to be taught at a highly applied level, i.e., no theory. The proposed course was too long and needed to be cut in half. The course needed to be broken up into multiple sessions based on the principle that "the mind can absorb only as much as the posterior can withstand" (direct quote from participant).

A 64-hour training was developed based on the input from professional and clientele focus group meetings. The workshop was conducted in four 2-day sessions held 2 weeks apart to minimize disruptions to producers' businesses. This Master Marketer training is now in its 11 th year, and although some subject matter and speakers have changed, the basic format has remained unaltered.

\section{Evaluation}

Personally, I thought evaluating programs was a waste of time when I began my Extension career. Now, I believe it may be the second most important activity (program development is first). I put evaluations into two classifications: soft and hard. Soft evaluations are done while the program is conducted and include knowledge gained, materials, speakers, etc. Hard evaluations are done 1-3 years following the program, with the primary purpose being to measure implementation and economic impact. Unfortunately, hard evaluations of educational programs have not been done in the past. However, I contend that they are critical to our future. Hard evaluations provide the evidence of the value of our efforts in a universal language (dollars) that can be used with legislatures and Congress to gain or maintain support. It also provides crucial insight on whether a programming effort is worth the time invested. We do both soft and hard evaluations of the Master Marketer Program. Participants are evaluated at the beginning and the end to determine knowledge gained, and speakers/ content is evaluated at the end of the second and fourth sessions. A $2 \frac{1}{2}$-year postattendance 
evaluation is conducted to determine implementation and economic impact. Results of these evaluations have been critical in adjusting program content and obtaining funding for developing additional support materials and programs.

\section{Benefits of Intensive Educational Programming}

Earlier, I indicated that I'd end with the benefits of intensive educational programming. In the Master Marketer Program, the benefits are in the results. A total of 18 Master Marketer trainings have been conducted. A 21/2-year postattendance survey has been performed on 15 of these classes. The survey response rate over the 15 classes was $62.5 \%$ and indicated that respondents had increased their returns on average more than $\$ 32,000$ annually based on what they had learned in the course. This represented a $4.2 \%$ increase in their gross returns. When you consider that the techniques taught can be used year after year, the impact grows substantially.

Some professionals would argue that a $4.2 \%$ increase in relative gross returns isn't statistically significant. However, I would argue that the increase in returns basically goes to net income, and it is highly important. For example, in a 2000 publication, large family farms were reported to have annual gross sales of $\$ 375,000$ and an associated net income of $\$ 45,233$ (ERS-USDA). A $4.2 \%$ increase in gross sales is $\$ 15,750$ dollars and is not a huge amount. However, if it all goes to income, it would be a $30 \%$ increase in net income, assuming a $15 \%$ tax bracket. Now that is significant!

Again, as I hypothesized earlier, intensive educational efforts that improve a clientele's bottom line create advocates, and these individuals or groups become vocal supporters. The Master Marketer Program is a perfect example of this. Over its 11 years of existence, more than $\$ 1.5$ million has been obtained in grants, registration fees, and sponsorships to support and expand these marketing/risk management programs. The support of commodity groups, both financial and verbal, has been leveraged to obtain federal funding.

However, the best example of the advocacy the Master Marketer Program has created is with the state legislature. In the 1997/1998 legislative session, our project group submitted a proposed initiative to create long term planning assistance for producers including a computerized tool and one-on-one assistance. The Chairman of the House Agriculture Committee selected that initiative to champion and expanded it to include marketing/risk management education. Extension receives $\$ 1.5 \mathrm{mil}$ lion annually from that initiative, most of which goes to our project group. The chairman was a graduate of the first Master Marketer class (1996) and continues to be a vocal supporter of the program.

I would be remiss not to mention two more details. First is another positive externality created by the Master Marketer Program for our profession. If we believe we do not have the expertise in Texas to teach a particular topic, we hire the best available person to ensure quality. Therefore, we are providing "consulting opportunities" for others in our profession. Finally, I have highlighted the Master Marketer Program, but it is just one of the intensive educational efforts being conducted in Texas by our group. Some of the other intensive educational programs include: long range planning assistance for agricultural producers and agribusinesses (Farm Assistance); a training that provides new producers with the tools necessary to construct a business plan, Tomorrow's Top Agricultural Producers Program; and an executive management program for agricultural operations, The Executive Program for Agricultural Producers.

In summary, future hard-dollar funding for our profession in Extension will continue to be under pressure. Maintaining and even enhancing funding is possible, but creative approaches will be required to obtain this result. Extensive programming needs to be streamlined and the delivery of materials to clientele made more efficiently. The focus of efforts in the future should center on applied research and intensive educational programming. Con- 
ducted effectively, these activities will generate soft-dollar support and create advocates for our programs. I believe that creating advocates is the cornerstone to our discipline being successful in the future.

Finally, I wish to thank the Association for this award. It is a great honor to be considered on the same level as current and past recipients.

\section{References}

Economic Research Service-United States Department of Agriculture (ERS-USDA). "A Safety Net for Farm Households." Agricultural Research Service, \#788, October 2000, Washington, DC.

Hoag, D.L. "Economic Principles for Saving the Cooperative Extension Service." Journal of Agricultural and Resource Economics 30,3(December 2005):397-410. 